\title{
Variabilidade temporal e espacial do tamanho de amostra da temperatura mínima do ar no Rio Grande do Sul, Brasil
}

\author{
Spatial and temporal variability of sample size to minimum air temperature in Rio Grande do Sul State, Brazil
}

\author{
Alberto Cargnelutti Filho ${ }^{1}$ Ronaldo Matzenauer ${ }^{2}$ Jaime Ricardo Tavares Maluf $^{3}$
}

\section{RESUMO}

Com o objetivo de verificar a existência de variabilidade temporal e espacial do tamanho de amostra da temperatura mínima do ar média mensal de trinta e sete municípios do Rio Grande do Sul, utilizaram-se os dados de temperatura mínima do ar do período de 1931 a 2000. Determinou-se o tamanho de amostra da temperatura mínima do ar média mensal em cada mês e município. Realizou-se análise de agrupamento dos meses e dos municípios pelo método hierárquico "vizinho mais distante". Há variabilidade do tamanho de amostra (número de anos) para a estimativa da temperatura mínima do ar média mensal no Estado do Rio Grande do Sul no tempo e no espaço. Maior tamanho de amostra, no Estado do Rio Grande do Sul, é necessário nos meses de maio, junho e julho, com diminuição gradativa em direção a janeiro e dezembro. Há variabilidade do tamanho de amostra entre os municípios do Estado do Rio Grande do Sul.

Palavras-chave: análise estatística, tamanho de amostra, temperatura mínima do ar, Sul do Brasil.

\section{ABSTRACT}

The aim of this work was to verify temporal and spatial variability of the size sample of the monthly average of air minimum temperature, in 37 localities of the Rio Grande do Sul State, Brazil. The minimum temperature data were collected from 1931 to 2000. It was calculated the sample size, in each month and locality. Localities and months were clustered by the complete linkage method. There are variability temporal and spatial of the size sample (number of years) of the monthly average of air minimum temperature in the Rio Grande do Sul State. Greater sample size occur in the months of May, June and July, with gradual reduction up to January and December. There are variability in the size sample among locaties in the Rio Grande do Sul State.

Key words: statistical analysis, sample size, air minimum temperature, Southern Brazil.

\section{INTRODUÇÃO}

O conhecimento do comportamento da precipitação pluvial, da temperatura, da umidade relativa do ar, da evaporação, da direção e velocidade do vento, da radiação solar global, de ocorrência de orvalho, de nevoeiro, de granizo, de geada e de neve, entre outros fenômenos, é um importante instrumento na tomada de decisões relacionadas às atividades agropecuárias, turísticas e esportivas. Entre essas variáveis climáticas, a temperatura do ar é fundamental, principalmente, em relação às atividades agropecuárias.

Diante de uma série de dados amostrais, além de gráficos e tabelas usados para representá-la, há necessidade de estimar os parâmetros da população de onde se obteve a amostra para conseguir informações sobre esta última. Entre essas estimativas, as obtidas por medidas de tendência central (média, mediana, moda) desacompanhadas de uma medida de variabilidade dos dados (amplitude, desvio padrão, variância, coeficiente de variação) são insuficientes para

\footnotetext{
${ }^{1}$ Departamento de Ciências Exatas, Faculdade de Ciências Agrárias e Veterinárias (FCAV), Universidade Estadual Paulista (UNESP), Via de Acesso Prof. Paulo Donato Castellane, s/n, 14884-900, Jaboticabal, SP, Brasil. E-mail: cargnelutti@fcav.unesp.br. Autor para correspondência.

${ }^{2}$ Fundação Estadual de Pesquisa Agropecuária (FEPAGRO), Rua Gonçalves Dias, 570, Bairro Menino Deus, 90130-060, Porto Alegre, RS, Brasil. E-mail: ronaldo-matzenauer@fepagro.rs.gov.br.

${ }^{3}$ Embrapa Trigo, Rodovia BR 285, km 174, 99001-970, Passo Fundo, RS, Brasil. E-mail: maluf@cnpt.embrapa.br.
} 
inferir sobre a confiabilidade de tais estimativas. Além dessas, as medidas de assimetria e curtose complementam a caracterização da série amostrada. Essas estimativas, em conjunto, possibilitam inferir sobre os parâmetros populacionais, com uma margem de erro conhecida.

A obtenção de todos os elementos de uma população possibilita calcular os parâmetros populacionais de uma variável, com ausência de erro. Porém, recursos financeiros, tempo, mão-de-obra e disponibilidade de dados dificultam a realização deste processo, necessitando estimar o parâmetro populacional por meio de medições realizadas em um determinado número de elementos da população (amostra). Fica evidente que a estimativa obtida a partir de uma amostra está associada a um erro. No entanto, processos de amostragem são utilizados a fim de definir a amostra cuja estimativa seja o mais próxima possível do parâmetro populacional, ou seja, com mínimo erro.

A inclusão de observações numa série temporal, dessas variáveis climáticas, altera as estimativas dos parâmetros populacionais que são desconhecidos. No entanto, por meio de uma amostra, podem ser estimados pontualmente ou por intervalo em torno da estimativa pontual e, desta forma, é importante conhecer a precisão de tal estimativa. A estimativa por ponto não permite saber o erro associado, enquanto que a estimativa por intervalo de um parâmetro populacional permite conhecer o grau de confiança na estimativa e o erro associado.

É comum o uso da média amostral como medida para caracterizar um conjunto de dados, porém a importância da variabilidade dos dados influencia na precisão de tal estimativa. Assim, um conjunto de dados com pouca variabilidade (homogêneo) necessitará de um menor tamanho de amostra para representar os mesmos, quando comparados a um grupo de dados heterogêneo.

Identificação de regiões homogêneas quanto à temperatura do ar (DINIZ et al., 2003), estimativas de probabilidade usando funções de distribuição de probabilidade teóricas em relação à temperatura do ar (ESTEFANEL et al., 1995; MOTA et al., 1999; CARGNELUTTI FILHO et al., 2006) têm sido desenvolvidas, enfatizando os benefícios no planejamento de atividades que minimizem riscos climáticos. Aplicações desses estudos em cultivos agrícolas (ESTEFANEL et al., 1994) e ainda específicos para as culturas do feijão (GONÇALVES et al., 1997; CARGNELUTTI FILHO et al., 2005), do arroz irrigado (MOTA et al., 1999; STEINMETZ et al., 2003) e do pepineiro (BURIOL et al., 2000a; BURIOL et al., 2000b) têm sido realizados. Porém, estudos de tamanho de amostra, relacionados a variáveis climáticas, são pouco conhecidos no Estado do Rio Grande do Sul. Além disso, tem-se adotado trinta anos como padrão para caracterizar as "normais climatológicas” das variáveis climáticas de uma região, sem, no entanto, considerar a variabilidade entre locais, tempo e entre variáveis. Assim, é importante determinar o tamanho ótimo de amostra (número de anos) necessário para estimar a temperatura mínima do ar média mensal, e, além disso, a variabilidade temporal e espacial deve ser considerada.

Ao se determinar o tamanho da amostra, em um determinado local e época do ano, necessário para caracterizar uma determinada variável, é preciso estabelecer um erro máximo aceitável com um determinado grau de confiança. No entanto, não há um valor que possa ser definido como erro máximo tolerável da estimativa da temperatura mínima do ar média mensal. Porém, o que deve ser considerado é a possibilidade de obter uma estimativa com máxima confiabilidade possível. Assim, neste estudo, fixou-se um erro máximo tolerável na estimativa da temperatura mínima do ar média mensal de $0,5^{\circ} \mathrm{C}$ com um grau de confiança (1- $\alpha$ ) de 95\%. É evidente que o tamanho da amostra aumenta com a diminuição do erro permitido, com o acréscimo do grau de confiança e com o aumento da variabilidade dos dados.

O objetivo deste trabalho foi verificar a variabilidade temporal e espacial do tamanho de amostra para a estimativa da temperatura mínima do ar média mensal de trinta e sete municípios do Rio Grande do Sul.

\section{MATERIAL E MÉTODOS}

Os dados de temperatura mínima do ar média mensal das 37 estações agrometeorológicas localizadas em trinta e sete municípios do Estado do Rio Grande do Sul foram obtidos no Banco de Dados do Laboratório de Agrometeorologia da Fundação Estadual de Pesquisa Agropecuária - Fepagro/SCT-RS e do Instituto Nacional de Meteorologia - INMET Porto Alegre. Os dados coletados referem-se ao período de 1931 a 2000 e totalizam 70 anos de observações. Em cada um dos 37 municípios, com a série temporal diária da temperatura mínima do ar, calculou-se a média mensal dos 12 meses do ano (janeiro até dezembro). Assim, obteve-se 444 séries temporais (37 municípios x 12 meses) com tamanho n=70 termos.

Aplicou-se o teste de Bartlett (STEEL et al., 1997) nos dados de temperatura mínima do ar média mensal para verificar a homogeneidade das variâncias entre os meses do ano (12 variâncias - variabilidade temporal) em cada um dos 37 locais (37 testes) e entre os locais (37 variâncias - variabilidade espacial) dentro de cada um dos doze meses (12 testes). 
Calculou-se o tamanho de amostra de cada uma das 444 séries de dados de temperatura mínima do ar média mensal para cada mês e município (12 meses $\mathrm{x}$ 37 municípios $=444$ séries temporais). Inicialmente, determinou-se a intensidade de amostragem (n ) para uma semi-amplitude do intervalo de confiança igual a $0,5^{\circ} \mathrm{C}$, com um grau de confiança de $95 \%$, pela expressão

$$
\mathrm{n}_{0}=\frac{\mathrm{t}_{\alpha / 2}^{2} \mathrm{~S}^{2}}{\text { erro }^{2}}
$$

(FONSECA \& MARTINS, 1995; SILVA et al., 1997; MUNIZ \&ABREU, 1999; STEVENSON, 2001; COSTANETO, 2002; BARBETTA et al., 2004; BUSSAB \& MORETTIN, 2004; SPIEGEL et al., 2004), na qual erro é a semi-amplitude do intervalo de confiança $\left(0,5^{\circ} \mathrm{C}\right)$ e $\mathrm{t}_{/ / 2}$ é o valor da tabela t de Student com (n-1) graus de liberdade e $\alpha=5 \%$ de probabilidade de erro e $S^{2}$ é a variância amostral.

Nas situações em que o tamanho ideal de amostra calculado for superior a 5\% da população amostrada (FONSECA \& MARTINS 1995; SILVA et al., 1997; MUNIZ \& ABREU, 1999; BARBETTAet al., 2004; BUSSAB \& MORETTIN, 2004; SPIEGEL et al., 2004) é conveniente calcular o tamanho ideal de amostra corrigido para população finita. Assim, aplicou-se a correção a fim de se obter o tamanho final da amostra (n) pela fórmula:

$$
\mathrm{n}=\frac{\mathrm{n}_{0}}{1+\frac{\mathrm{n}_{0}-1}{\mathrm{~N}}}
$$

na qual $\mathrm{N}=70$ anos. Se $\mathrm{n}_{0}$ for menor que $5 \%$ de $\mathrm{N}$, a correção torna-se desprezível e o tamanho de amostra é aquele obtido em $\mathrm{n}_{0}$ (MUNIZ \& ABREU, 1999).

A partir do tamanho de amostra em cada mês e município do Estado do Rio Grande do Sul determinou-se a matriz de distância euclidiana média padronizada entre os doze meses. Esta matriz foi utilizada como medida de dissimilaridade para a análise de agrupamento dos meses pelo método hierárquico “vizinho mais distante” (CRUZ \& REGAZZI, 1997), adotando-se o nível de $60 \%$ de similaridade como critério para separação dos grupos. Também determinou-se a matriz de distância euclidiana média padronizada entre os 37 municípios, que foi utilizada como medida de dissimilaridade para a análise de agrupamento dos municípios pelo método hierárquico “vizinho mais distante” (CRUZ \& REGAZZI, 1997), adotando-se o nível de $60 \%$ de similaridade como critério para separação dos grupos. As análises foram realizadas com o auxílio do aplicativo Office Excel e do programa Genes (CRUZ, 2001).

\section{RESULTADOS E DISCUSSÃO}

O teste de Bartlett (STEEL et al., 1997) aplicado entre as variâncias dos doze meses em cada local constatou que estas foram heterogêneas nos trinta e sete locais, o que indica tamanho de amostra diferenciado entre cada um dos meses (Tabela 1). Isso permite inferir presença de variabilidade temporal do tamanho de amostra da temperatura mínima do ar média mensal. A identificação de meses com comportamentos similares pode ser verificada por meio de análise de agrupamento.

Entre as variâncias dos trinta e sete locais, em cada mês, o teste de Bartlett revelou variâncias homogêneas nos meses de maio, junho e julho, o que indica que o tamanho de amostra para estimar a temperatura mínima do ar média mensal pode ser o mesmo para os trinta e sete locais estudados. Já para os demais nove meses, a variância entre locais foi heterogênea, o que revela necessidade de estimar o tamanho de amostra em cada local. Isso permite inferir presença de variabilidade espacial e possibilidade de agrupar municípios de comportamento semelhante.

De maneira geral, estes resultados indicam a necessidade de utilizar a maior das 444 variâncias obtidas entre a combinação dos trinta e sete locais e doze meses para estimar um tamanho de amostra único para esses locais e meses, com um determinado erro tolerável a um determinado intervalo de confiança. Por outro lado, a variabilidade existente indica a possibilidade de identificar variabilidade do tamanho de amostra no tempo e no espaço. Então, a estimativa do tamanho de amostra de cada combinação local e mês possibilita a identificação de meses e locais com maior e menor tamanho de amostra necessário para estimar a temperatura mínima do ar média mensal com um determinado erro e confiança.

O tamanho de amostra para a estimativa da temperatura mínima do ar média mensal em cada mês e município, com semi-amplitude do intervalo de confiança igual a $0,5^{\circ} \mathrm{C}$ e grau de confiança de $95 \%$, oscilou de 11 anos no mês de janeiro em Bagé a 38 anos no mês de julho em Ijuí e no mês de maio em Iraí (Tabela 2). Portanto, em relação a Bagé, pode-se inferir com $95 \%$ de confiança que a estimativa da média $(\hat{\mu})$ da temperatura mínima do ar média mensal obtida com onze anos de observações no mês de janeiro é $\quad \pm 0,5^{\circ} \mathrm{C}$. Esses resultados confirmam a variabilidade existente entre meses dentro dos locais (temporal) e entre locais dentro de meses (espacial). Então, 38 anos de observações forneceriam estimativas de temperatura mínima do ar média mensal com 95\% de confiabilidade de que o erro máximo é de $0,5^{\circ} \mathrm{C}$, independentemente do mês e do local. 
Tabela 1 - Valor calculado da estatística do teste de Bartlett $\left(\chi_{\text {calc }}^{2}\right)$ das variâncias da temperatura mínima do ar média mensal de cada mês entre os locais e das variâncias de cada local entre os doze meses do ano. Porto Alegre, RS, 2005.

\begin{tabular}{|c|c|c|c|c|c|}
\hline Local & $\chi_{\text {calc }}^{2}$ & & Mês & $\chi_{\text {calc }}^{2}$ & \\
\hline Alegrete & 74,48 & $*$ & Janeiro & 131,23 & * \\
\hline Bagé & 74,64 & $*$ & Fevereiro & 98,73 & $*$ \\
\hline Bento Gonçalves & 55,02 & * & Março & 83,74 & $*$ \\
\hline Bom Jesus & 70,71 & * & Abril & 60,39 & * \\
\hline Caçapava do Sul & 40,29 & * & Maio & 32,64 & ns \\
\hline Cachoeira do Sul & 63,96 & * & Junho & 37,38 & ns \\
\hline Caxias do Sul & 58,69 & * & Julho & 30,38 & ns \\
\hline Cruz Alta & 63,07 & $*$ & Agosto & 53,56 & $*$ \\
\hline Encruzilhada do Sul & 64,71 & $*$ & Setembro & 55,12 & $*$ \\
\hline Farroupilha & 67,21 & $*$ & Outubro & 58,07 & $*$ \\
\hline Guaporé & 72,90 & * & Novembro & 106,64 & * \\
\hline Ijuí & 83,20 & * & Dezembro & 104,00 & * \\
\hline Iraí & 30,23 & * & & & \\
\hline Júlio de Castilhos & 27,65 & * & & & \\
\hline Lagoa Vermelha & 81,17 & * & & & \\
\hline Osório & 39,54 & $*$ & & & \\
\hline Palmeira das Missões & 45,64 & $*$ & & & \\
\hline Passo Fundo & 89,42 & * & & & \\
\hline Pelotas & 26,60 & * & & & \\
\hline Porto Alegre & 94,57 & * & & & \\
\hline Rio Grande & 70,61 & $*$ & & & \\
\hline Santa Maria & 76,94 & * & & & \\
\hline Santana do Livramento & 54,88 & * & & & \\
\hline Santa Rosa & 60,27 & * & & & \\
\hline Santa Vitória do Palmar & 39,57 & * & & & \\
\hline Santiago & 33,80 & * & & & \\
\hline Santo Ângelo & 34,68 & * & & & \\
\hline São Borja & 91,11 & * & & & \\
\hline São Francisco de Paula & 33,84 & $*$ & & & \\
\hline São Gabriel & 45,76 & * & & & \\
\hline São Luiz Gonzaga & 63,66 & * & & & \\
\hline Tapes & 40,81 & * & & & \\
\hline Taquari & 83,25 & * & & & \\
\hline Torres & 65,59 & * & & & \\
\hline Uruguaiana & 86,53 & $*$ & & & \\
\hline Vacaria & 56,36 & * & & & \\
\hline Veranópolis & 63,06 & * & & & \\
\hline
\end{tabular}

* Significativo a 5\% de probabilidade pelo teste de Bartlett. ${ }^{\text {ns }}=$ Não-significativo

De um modo geral, maior tamanho de amostra é necessário nos meses de maio, junho e julho, diminuindo gradativamente em direção a janeiro e dezembro, indicando, maior e menor variabilidade, respectivamente (Tabela 2). Esses resultados coincidem, respectivamente, com meses de menor e maior temperatura máxima do ar média decendial (CARGNELUTTI FILHO et al., 2005) e temperatura mínima do ar média decendial (CARGNELUTTI FILHO et al., 2006). Portanto, ao usar o mesmo número de anos em todos os meses para estimar a temperatura mínima do ar média mensal, a precisão da estimativa nos meses de maio, junho e julho é menor em relação aos demais meses do ano.

Caso fossem consideradas outras combinações de semi-amplitude do intervalo de confiança e do grau de confiança para calcular o tamanho de amostra, seria esperado comportamento semelhante, ou seja, que os meses de maio, junho e julho fossem os de maior tamanho de amostra no Estado do Rio Grande do Sul, pelo fato de a maior variabilidade dos dados de temperatura mínima do ar média mensal ocorrer nesses meses.

A formação de três grupos de meses foi possível pelo método hierárquico do vizinho mais distante, utilizando-se $60 \%$ de similaridade como critério para definição desses grupos (Figura 1). Meses que compuseram o grupo um (janeiro, fevereiro, março, novembro e dezembro) são os meses com menor variabilidade da temperatura mínima do ar média mensal entre os anos, necessitando menor tamanho de amostra (número de anos) para estimar a temperatura mínima do ar média mensal. Em outro extremo, no grupo três, estão os meses de maio, junho e julho, com maior tamanho de amostra. A maior oscilação da temperatura mínima do ar média mensal entre os anos explica tal comportamento. Os meses de abril, agosto, setembro e outubro compõem o grupo dois e estão em situação intermediária. Estes resultados confirmam presença de variabilidade temporal do tamanho da amostra e a necessidade de considerar número diferenciado de anos de observação para estimar a temperatura mínima do ar média mensal.

A formação de dois grupos de municípios foi possível pelo método hierárquico do vizinho mais distante, utilizando-se $60 \%$ de similaridade como critério para definição desses grupos (Figura 2 e Tabela 3). Os trinta e um municípios que compuseram o grupo um são os locais com menor variabilidade da temperatura mínima do ar média mensal entre os meses necessitando menor tamanho de amostra (número de anos) para estimar a temperatura mínima do ar média mensal. Os outros seis municípios formaram o grupo dois, caracterizado pela presença de maior variabilidade e, como conseqüência, pelo maior tamanho de amostra. Esses resultados confirmam presença de variabilidade espacial do tamanho da amostra e não parecem estar associados à localização geográfica. 
Tabela 2 - Tamanho da amostra (número de anos) da temperatura mínima do ar média mensal em localidades do Estado do Rio Grande do Sul com 95\% de confiança e semi-amplitude do intervalo de confiança de 0,5 ${ }^{\circ} \mathrm{C}$. Porto Alegre, RS, 2005.

\begin{tabular}{|c|c|c|c|c|c|c|c|c|c|c|c|c|c|c|c|}
\hline \multirow[t]{2}{*}{ Local } & \multicolumn{12}{|c|}{ Mês } & \multirow[t]{2}{*}{ Máximo } & \multirow[t]{2}{*}{ Mínimc } & \multirow[t]{2}{*}{ Média } \\
\hline & jan & fev & mar & abr & mai & jun & jul & ago & set & out & nov & dez & & & \\
\hline Alegrete & 14 & 16 & 20 & 28 & 35 & 33 & 34 & 24 & 24 & 26 & 25 & 17 & 35 & 14 & 25 \\
\hline Bagé & 11 & 14 & 17 & 23 & 30 & 28 & 30 & 22 & 21 & 23 & 18 & 15 & 30 & 11 & 21 \\
\hline Bento Gonçalves & 17 & 16 & 17 & 29 & 31 & 27 & 33 & 25 & 20 & 26 & 19 & 20 & 33 & 16 & 23 \\
\hline Bom Jesus & 17 & 16 & 16 & 24 & 32 & 29 & 33 & 26 & 22 & 24 & 18 & 14 & 33 & 14 & 23 \\
\hline Caçapava do Sul & 13 & 14 & 25 & 21 & 28 & 25 & 28 & 22 & 19 & 25 & 20 & 21 & 28 & 13 & 22 \\
\hline Cachoeira do Sul & 15 & 21 & 15 & 29 & 35 & 28 & 30 & 22 & 24 & 30 & 21 & 17 & 35 & 15 & 24 \\
\hline Caxias do Sul & 14 & 15 & 15 & 24 & 28 & 26 & 31 & 25 & 19 & 24 & 18 & 17 & 31 & 14 & 21 \\
\hline Cruz Alta & 14 & 12 & 16 & 25 & 29 & 27 & 31 & 23 & 20 & 23 & 17 & 17 & 31 & 12 & 21 \\
\hline Encruzilhada do Sul & 14 & 14 & 17 & 21 & 34 & 24 & 29 & 20 & 22 & 24 & 18 & 16 & 34 & 14 & 21 \\
\hline Farroupilha & 16 & 19 & 15 & 29 & 32 & 28 & 29 & 25 & 18 & 25 & 17 & 15 & 32 & 15 & 22 \\
\hline Guaporé & 14 & 15 & 19 & 30 & 31 & 29 & 31 & 25 & 19 & 24 & 16 & 18 & 31 & 14 & 23 \\
\hline Ijuí & 15 & 16 & 21 & 27 & 32 & 31 & 38 & 26 & 24 & 27 & 18 & 17 & 38 & 15 & 24 \\
\hline Iraí & 24 & 26 & 25 & 35 & 38 & 31 & 37 & 32 & 27 & 35 & 32 & 31 & 38 & 24 & 31 \\
\hline Júlio de Castilhos & 20 & 16 & 16 & 22 & 27 & 25 & 28 & 23 & 19 & 25 & 21 & 19 & 28 & 16 & 22 \\
\hline Lagoa Vermelha & 15 & 15 & 16 & 29 & 31 & 25 & 32 & 25 & 19 & 21 & 15 & 14 & 32 & 14 & 21 \\
\hline Osório & 19 & 25 & 25 & 26 & 31 & 30 & 32 & 25 & 24 & 29 & 17 & 17 & 32 & 17 & 25 \\
\hline Palmeira das Missões & 16 & 13 & 23 & 25 & 27 & 27 & 28 & 23 & 15 & 24 & 19 & 19 & 28 & 13 & 22 \\
\hline Passo Fundo & 12 & 12 & 12 & 22 & 27 & 25 & 29 & 22 & 19 & 22 & 13 & 12 & 29 & 12 & 19 \\
\hline Pelotas & 24 & 21 & 23 & 32 & 35 & 33 & 31 & 26 & 30 & 32 & 24 & 26 & 35 & 21 & 28 \\
\hline Porto Alegre & 11 & 12 & 13 & 21 & 29 & 28 & 28 & 20 & 17 & 19 & 12 & 13 & 29 & 11 & 19 \\
\hline Rio Grande & 16 & 18 & 19 & 20 & 31 & 30 & 29 & 21 & 18 & 24 & 13 & 13 & 31 & 13 & 21 \\
\hline Santa Maria & 14 & 16 & 16 & 25 & 32 & 32 & 33 & 23 & 21 & 26 & 22 & 16 & 33 & 14 & 23 \\
\hline Santana do Livramento & 18 & 15 & 23 & 27 & 31 & 30 & 32 & 25 & 23 & 27 & 21 & 14 & 32 & 14 & 24 \\
\hline Santa Rosa & 19 & 14 & 18 & 29 & 33 & 31 & 33 & 27 & 24 & 27 & 25 & 18 & 33 & 14 & 25 \\
\hline Santa Vitória do Palmar & 15 & 14 & 18 & 20 & 28 & 25 & 25 & 14 & 18 & 20 & 17 & 17 & 28 & 14 & 19 \\
\hline Santiago & 25 & 26 & 17 & 25 & 32 & 27 & 31 & 25 & 20 & 29 & 21 & 18 & 32 & 17 & 25 \\
\hline Santo Ângelo & 29 & 18 & 19 & 27 & 32 & 32 & 33 & 28 & 28 & 25 & 24 & 22 & 33 & 18 & 27 \\
\hline São Borja & 13 & 13 & 20 & 27 & 33 & 35 & 34 & 25 & 22 & 29 & 20 & 20 & 35 & 13 & 24 \\
\hline São F. de Paula & 16 & 17 & 17 & 26 & 28 & 24 & 28 & 29 & 21 & 26 & 22 & 21 & 29 & 16 & 23 \\
\hline São Gabriel & 18 & 21 & 23 & 30 & 34 & 35 & 32 & 28 & 24 & 29 & 25 & 20 & 35 & 18 & 26 \\
\hline São Luiz Gonzaga & 13 & 14 & 17 & 27 & 30 & 29 & 32 & 25 & 22 & 27 & 19 & 21 & 32 & 13 & 23 \\
\hline Tapes & 16 & 17 & 18 & 25 & 30 & 30 & 30 & 21 & 22 & 23 & 20 & 20 & 30 & 16 & 23 \\
\hline Taquari & 12 & 15 & 16 & 25 & 32 & 30 & 31 & 23 & 20 & 22 & 17 & 15 & 32 & 12 & 21 \\
\hline Torres & 12 & 13 & 12 & 20 & 25 & 28 & 26 & 16 & 20 & 18 & 14 & 16 & 28 & 12 & 18 \\
\hline Uruguaiana & 12 & 16 & 17 & 20 & 29 & 32 & 33 & 21 & 19 & 25 & 16 & 14 & 33 & 12 & 21 \\
\hline Vacaria & 15 & 19 & 18 & 26 & 31 & 28 & 33 & 24 & 18 & 22 & 18 & 18 & 33 & 15 & 22 \\
\hline Veranópolis & 13 & 17 & 14 & 24 & 28 & 26 & 29 & 23 & 24 & 23 & 14 & 14 & 29 & 13 & 21 \\
\hline Máximo & 29 & 26 & 25 & 35 & 38 & 35 & 38 & 32 & 30 & 35 & 32 & 31 & 38 & - & - \\
\hline Mínimo & 11 & 12 & 12 & 20 & 25 & 24 & 25 & 14 & 15 & 18 & 12 & 12 & - & 11 & - \\
\hline Média & 16 & 16 & 18 & 26 & 31 & 29 & 31 & 24 & 21 & 25 & 19 & 18 & - & - & 23 \\
\hline
\end{tabular}




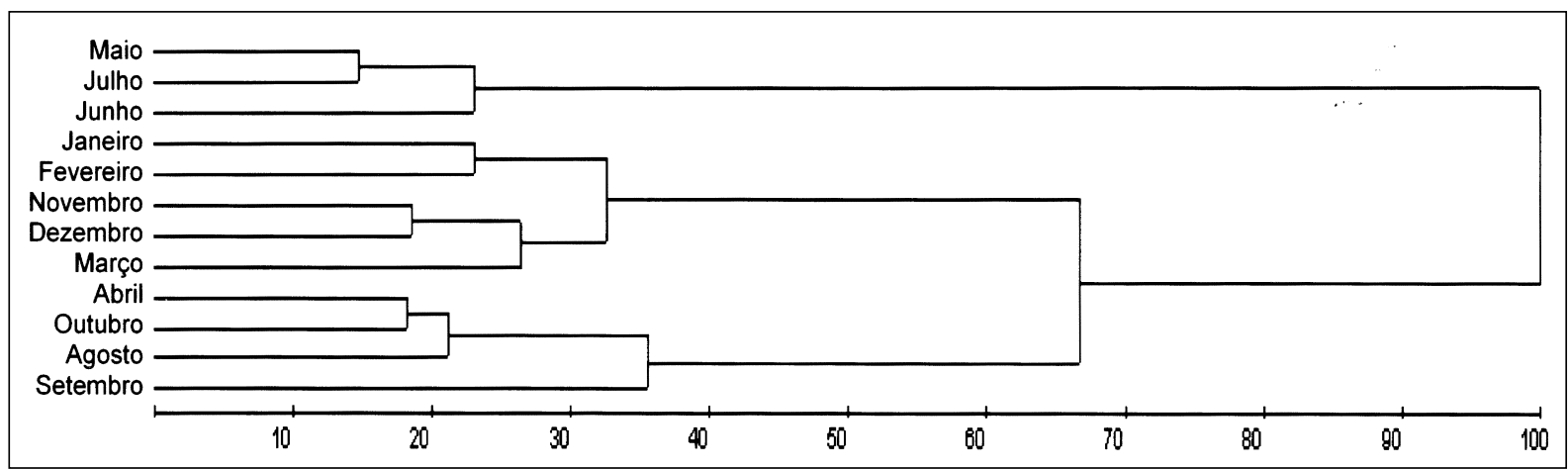

Figura 1 - Dendrograma da dissimilaridade da temperatura mínima do ar média mensal entre os meses do ano no Estado do Rio Grande do Sul obtido pelo método de agrupamento "vizinho mais distante”, baseado na distância euclidiana média padronizada. Porto Alegre, RS, 2005.

De modo geral, independentemente do grupo ao qual o município pertence, os meses de maio, junho e julho necessitam maior tamanho de amostra, diminuindo gradativamente em direção a janeiro e dezembro (Tabela 3).
Esses resultados indicam que com até 38 anos de observações, valor superior ao utilizado nas normais climatológicas é suficiente para estimar a temperatura mínima do ar média mensal para uma semiamplitude do intervalo de confiança igual a $0,5^{\circ} \mathrm{C}$, com

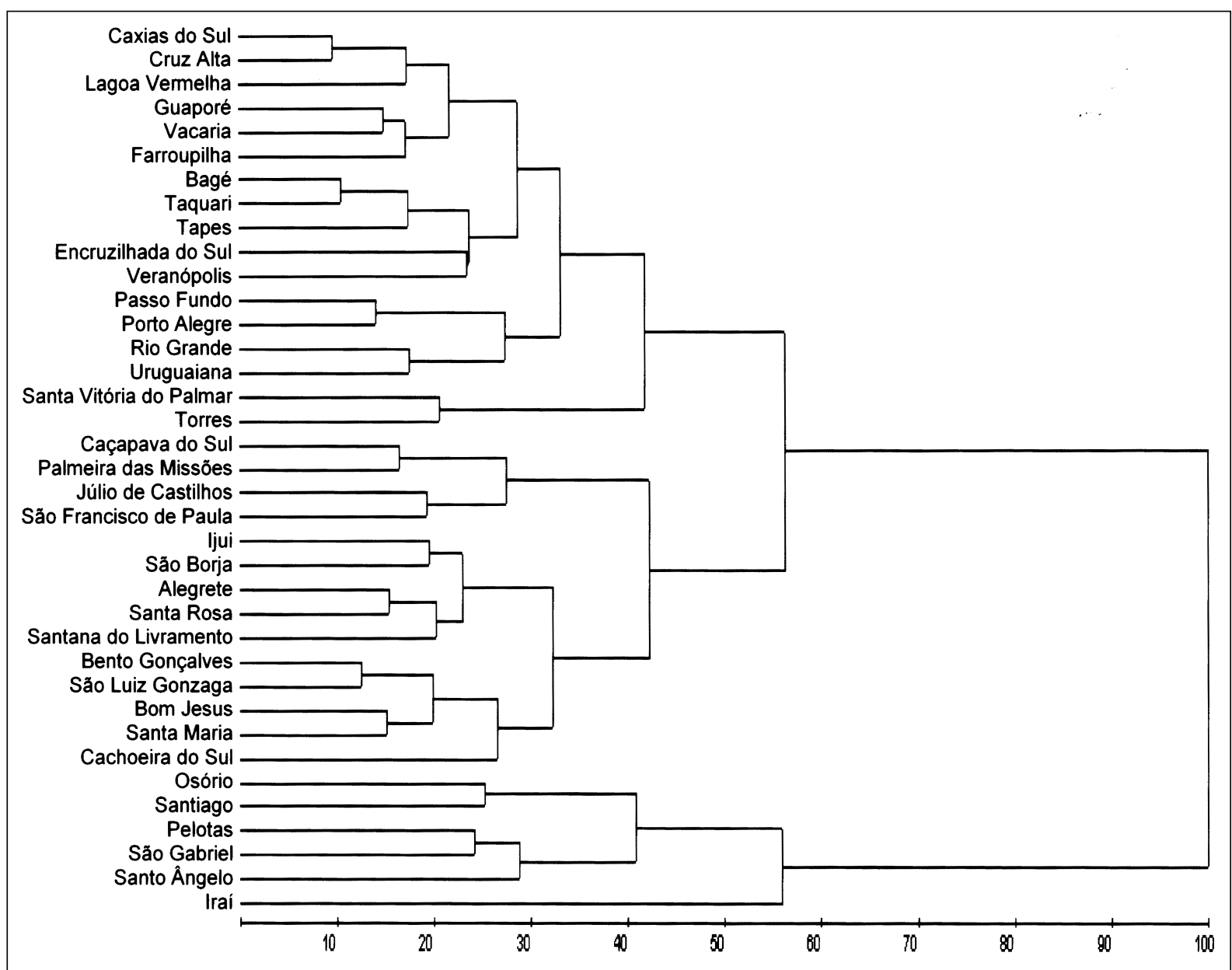

Figura 2 - Dendrograma da dissimilaridade da temperatura mínima do ar média mensal, entre 37 municípios do Estado do Rio Grande do Sul obtido pelo método de agrupamento "vizinho mais distante”, baseado na distância euclidiana média padronizada. Porto Alegre, RS, 2005 
Tabela 3 - Máximo, mínimo e média do tamanho de amostra (número de anos) da temperatura mínima do ar média mensal, com 95\% de confiança e semi-amplitude do intervalo de confiança de $0,5^{\circ} \mathrm{C}$, em cada mês e em cada grupo de municípios do Estado do Rio Grande do Sul, obtidos pelo método de agrupamento “vizinho mais distante”. Porto Alegre, RS, 2005.

\begin{tabular}{|c|c|c|c|c|c|c|c|c|c|c|c|c|c|}
\hline \multirow[t]{2}{*}{ Grupo $^{(1)}$} & \multirow[t]{2}{*}{ Estatística } & \multicolumn{12}{|c|}{ Mês } \\
\hline & & jan & fev & mar & abr & mai & jun & jul & ago & set & out & nov & dez \\
\hline 1 & Máximo & 20 & 21 & 25 & 30 & 35 & 35 & 38 & 29 & 24 & 30 & 25 & 21 \\
\hline 1 & Mínimo & 11 & 12 & 12 & 20 & 25 & 24 & 25 & 14 & 15 & 18 & 12 & 12 \\
\hline 1 & Média & 15 & 15 & 17 & 25 & 30 & 28 & 31 & 23 & 20 & 24 & 18 & 17 \\
\hline 2 & Máximo & 29 & 26 & 25 & 35 & 38 & 35 & 37 & 32 & 30 & 35 & 32 & 31 \\
\hline 2 & Mínimo & 18 & 18 & 17 & 25 & 31 & 27 & 31 & 25 & 20 & 25 & 17 & 17 \\
\hline 2 & Média & 23 & 23 & 22 & 29 & 34 & 31 & 33 & 27 & 25 & 30 & 24 & 22 \\
\hline
\end{tabular}

(1) 1: Caxias do Sul, Cruz Alta, Lagoa Vermelha, Guaporé, Vacaria, Farroupilha, Bagé, Taquari, Tapes, Encruzilhada do Sul, Veranópolis, Passo Fundo, Porto Alegre, Rio Grande, Uruguaiana, Santa Vitória do Palmar, Torres, Caçapava do Sul, Palmeira das Missões, Júlio de Castilhos, São Francisco de Paula, Ijuí, São Borja, Alegrete, Santa Rosa, Santana do Livramento, Bento Gonçalves, São Luiz Gonzaga, Bom Jesus, Santa Maria, Cachoeira do Sul.

2: Osório, Santiago, Pelotas, São Gabriel, Santo Ângelo, Iraí.

um grau de confiança de 95\%. Portanto, as estimativas de normais climatológicas desses locais, baseadas em 30 anos de observações, possuem uma semi-amplitude do intervalo de confiança menor ou maior que $0,5^{\circ} \mathrm{C}$, com um grau de confiança de $95 \%$. Assim, o uso de 30 anos, de forma generalizada, não contempla a variabilidade dos dados de cada local e época do ano, levando a estimativas com erros diferenciados.

\section{CONCLUSÃO}

Há variabilidade do tamanho de amostra (número de anos) para a estimativa da temperatura mínima do ar média mensal no Estado do Rio Grande do Sul no tempo e no espaço. Maior tamanho de amostra, no Estado do Rio Grande do Sul, é necessário nos meses de maio, junho e julho, com diminuição gradativa em direção a janeiro e dezembro. Há variabilidade do tamanho de amostra entre os municípios do Estado do Rio Grande do Sul.

\section{REFERÊNCIAS}

BARBETTA, P.A. et al. Estatística para cursos de engenharia e informática. São Paulo: Atlas, 2004. 410p.

BURIOL, G.A. et al. Condições térmicas para o cultivo do pepineiro na região do baixo vale do Taquari, RS: 1. Temperaturas baixas limitantes. Pesquisa Agropecuária Gaúcha, Porto Alegre, v.6, n.2, p.205-213, 2000a.

BURIOL, G.A. et al. Condições térmicas para o cultivo do pepineiro na região do baixo vale do Taquari, RS: 2 . Temperatura máxima e soma térmica. Pesquisa Agropecuária Gaúcha, Porto Alegre, v.6, n.2, p.215-223, 2000b.
BUSSAB, W.O.; MORETTIN, P.A. Estatística básica. 5.ed. São Paulo: Saraiva, 2004. 526p.

CARGNELUTTI FILHO, A. et al. Estimativa da temperatura mínima média decendial do ar no Estado do Rio Grande do Sul. Pesquisa Agropecuária Brasileira, Brasília, v.41, prelo, 2006.

CARGNELUTTI FILHO, A. et al. Temperaturas máximas prejudiciais ao feijoeiro no Estado do Rio Grande do Sul, Brasil. Ciência Rural, Santa Maria, v.35, n.5, p.1019-1026, 2005.

COSTA-NETO, P.L.O. Estatística. 2.ed. São Paulo: Edgard Blücher, 2002. 266p.

CRUZ, C.D. Programa genes - versão Windows: aplicativo computacional em genética e estatística. Viçosa: UFV, 2001. 648p.

CRUZ, C.D.; REGAZZI, A.J. Modelos biométricos aplicados ao melhoramento genético. 2.ed. Viçosa: UFV, 1997. 390p.

DINIZ, G.B. et al. Identificação de regiões homogêneas de temperaturas máxima e mínima do Rio Grande do Sul. Revista Brasileira de Agrometeorologia, Santa Maria, v.11, n.2, p.303-312, 2003.

ESTEFANEL, V. et al. Estimativa da duração da temperatura do ar acima de determinados níveis térmicos em Santa Maria, RS. Revista Brasileira de Agrometeorologia, Santa Maria, v.3, n.1, p.121-127, 1995.

ESTEFANEL, V. et al. Probabilidade de ocorrência de temperaturas máximas do ar prejudiciais aos cultivos agrícolas em Santa Maria, RS. Revista Brasileira de Agrometeorologia, Santa Maria, v.2, n.1, p.57-63, 1994.

FONSECA, J.S.; MARTINS, G.A. Curso de estatística. 5.ed. São Paulo: Atlas, 1995. 317p.

GONÇALVES, S.L. et al. Probabilidade de ocorrência de temperaturas superiores a $30^{\circ} \mathrm{C}$ no florescimento do feijoeiro 
(Phaseolus vulgaris L), cultivado na safra das águas no Estado do Paraná. Revista Brasileira de Agrometeorologia, Santa Maria, v.5, n.1, p.99-107, 1997.

MOTA, F.S. et al. Probabilidade de ocorrência de dias com temperaturas iguais ou superiores a $35^{\circ} \mathrm{C}$ no florescimento do arroz no Rio Grande do Sul. Revista Brasileira de Agrometeorologia, Santa Maria, v.7, n.1, p.147-149, 1999.

MUNIZ, J.A.; ABREU, A.R. Técnicas de amostragem. Lavras: UFLA/FAEPE, 1999. 102p.

SILVA, E.M. et al. Estatística para cursos de: Economia, Administração e Ciências Contábeis. 2.ed. São Paulo: Atlas, 1997. 195p.
SPIEGEL, R.A. et al. Probabilidade e estatística. 2.ed. Porto Alegre: Bookman, 2004. 398p.

STEEL, R.G.D. et al. Principles and procedures of statistics a biometrical approach. 3.ed. Nova York: McGraw-Hill, 1997. 666p.

STEINMETZ, S. et al. Probabilidade de ocorrência de temperaturas mínimas do ar durante o período reprodutivo do arroz irrigado, na metade norte do Estado do Rio Grande do Sul. Revista Brasileira de Agrometeorologia, Santa Maria, v.11, n.1, p.107-121, 2003.

STEVENSON, W.J. Estatística aplicada à Administração. São Paulo: Harbra, 2001. 495p. 